\title{
Effect of landscape type, elevation, vegetation period, and taxonomic plant identification level on diet preferences of Alpine mountain hares (Lepus timidus varronis)
}

\author{
Stéphanie C. Schai-Braun ${ }^{1}$ (D) $\cdot$ Katharina Lapin ${ }^{2,3} \cdot$ Karl-Georg Bernhardt $^{2} \cdot$ Paulo C. Alves $^{4,5} \cdot$ Klaus Hackländer $^{1}$
}

Received: 11 September 2019 / Revised: 27 January 2020 / Accepted: 9 June 2020 / Published online: 30 June 2020

(C) The Author(s) 2020

\begin{abstract}
Diet is important for understanding the ecology and evolution of populations. When examining animals' diets, the lowest taxonomic rank (i.e., species level) is generally used. However, it is questionable whether dietary description varies with respect to the plant taxonomy or with the extent of plant species diversity in landscapes. We studied the diet of the Alpine mountain hare (Lepus timidus varronis) by analyzing the botanical composition of fecal pellets and comparing the results with the availability of food plants. Overall, Alpine mountain hares selected ligneous plants, whereas grasses were neutrally consumed or avoided. Plant identification at the genus and family level revealed the most information, whereas little additional information was gleaned by identifying food plants at the species level. In low-diversity spruce forests and at higher elevations, hares exhibited greater diet breadth compared to high-diversity vegetative mosaics or at lower elevations, even if they had access to the same types of plants. This is likely due to the hares' need to diversify their diet when plant quantity is low. Greater diet breadth and selection of a larger number of different plant types at the beginning of the plant vegetation growth period suggested that more food plants suitable for Alpine mountain hares were available during this time compared to the end of the vegetation period.
\end{abstract}

Keywords Alps $\cdot$ Food plants $\cdot$ Habitat diversity $\cdot$ Herbivorous mammals $\cdot$ Lagomorpha $\cdot$ Taxonomic rank

Electronic supplementary material The online version of this article (https://doi.org/10.1007/s10344-020-01398-7) contains supplementary material, which is available to authorized users.

Stéphanie C. Schai-Braun stephanie.schai-braun@boku.ac.at

1 Institute of Wildlife Biology and Game Management, Department of Integrative Biology and Biodiversity Research, University of Natural Resources and Life Sciences, Vienna, Gregor-Mendel-Strasse 33, 1180 Vienna, Austria

2 Institute of Botany, Department of Integrative Biology and Biodiversity, University of Natural Resources and Life Sciences, Vienna, Gregor-Mendel-Strasse 33, 1180 Vienna, Austria

3 Federal Research and Training Centre for Forest, Natural Hazards and Landscape, Seckendorff-Gudent-Weg 8, 1131 Vienna, Austria

4 Departamento de Biologia, Faculdade de Ciências da Universidade do Porto, Rua do Campo Alegre s/n, 4169-007 Porto, Portugal

5 CIBIO, Centro de Investigação em Biodiversidade e Recursos Genéticos, InBIO Laboratório Associado, Universidade do Porto, Campus de Vairão, 4485-661 Vairão, Portugal

\section{Introduction}

Diet characterizes a central aspect of a species' ecological niche (Simberloff and Dayan 1991). It compels the metabolic rates of organisms (Brown et al. 2004) and determines the functional positions and trophic interactions of species in ecosystems (Duffy 2002). Diet may be significant for species diversification (Price et al. 2012; Cantalapiedra et al. 2014) and macroecological distribution (Kissling et al. 2009, 2012). When examining dietary composition - if taxonomic identification is possible - the lowest taxonomic rank (i.e., species level) is typically used (e.g., Schai-Braun et al. 2015; Erickson et al. 2017; Szép et al. 2018), with higher taxonomic ranks employed if identification at the species level is not possible (e.g., Schai-Braun et al. 2015; Erickson et al. 2017; Szép et al. 2018). This is generally considered to amount to a loss of information. It has been shown, however, that some species are selective in regard to dietary items at different levels of taxonomy (e.g., snakes; Halstead et al. 2008). It therefore seems possible that detectability of dietary composition may vary with respect to taxonomy rank. Furthermore, it is questionable whether higher taxonomic ranks inevitably 
correspond to direct loss of information and hence are to be avoided a priori.

Dietary composition for the same species can vary across the greater landscape as habitats, and with them the availability of certain food types, change (e.g., Nissen et al. 2013; Requier et al. 2015). For example, the diet of roe deer (Capreolus capreolus) inhabiting agricultural areas consists of a completely different flora than that of roe deer living in coniferous forests (Cornelis et al. 1999). Moreover, animals select or avoid different food types depending on food availability (Krebs 1989). Habitat diversity seems to have an inconsistent influence on diet breadth, however. For example, the diet breadth of common kestrels (Falco tinnunculus) correlates negatively with landscape heterogeneity (NavarroLópez and Fargallo 2015), whereas for omnivorous carnivores, habitat diversity correlates positively with dietary diversity (Kauhala and Ihalainen 2014). It remains unclear whether specific trends concerning diet breadth are applicable to different foraging strategies (i.e., carnivores, omnivores, or herbivores). Furthermore, it is likely that the dietary composition of herbivores varies with the extent of plant species diversity in a given landscape.

The diet of Lepus species typically consists of grasses and herbs during summer or in lowland areas (Schai-Braun and Hackländer 2016). At higher elevations or during winter months, Lepus switch to browsing on wooden plant parts such as twigs, branches, and bark (Schai-Braun and Hackländer 2016). The European hare (Lepus europaeus) has a strong selection for weed and grasses in spring, i.e., at the beginning of the vegetation growth period, compared to the rest of the year (Schai-Braun et al. 2015). While the diet selection of some Lepus species such as the North American snowshoe hare (Lepus americanus, e.g., Seccombe-Hett and Turkington 2008; Smith et al. 1988) and the European hare (e.g., Jennings et al. 2006) has been examined, few diet selection studies have hitherto been conducted on mountain hares (Lepus timidus, found in Europe and Asia) as this species lives in areas not readily accessible to humans. Mountain hares are grazers during the plant growing season, with plant species determined as food sources including ling (Calluna vulgaris), cotton grass (Eriophorum spp.), and various other grasses (Hewson 1962; Johannessen and Samset 1994; Hulbert and Iason 1996; Dingerkus and Montgomery 2001). During the plants' dormant season, mountain hares transition to browsing on items such as gorse (Ulex europaeus), juniper (Juniperis communis), and soft rush (Juncus effuses; Hewson 1962; Johannessen and Samset 1994; Hulbert and Iason 1996; Dingerkus and Montgomery 2001). Roughly categorized, the recorded diet for the subspecies Alpine mountain hare (L. t. varronis) consists of gymnosperms (such as conifers, $47.0 \%$ ), graminoids (grass-like plants, $32.5 \%$ ), dwarf shrubs (short woody plants, $8.5 \%$ ), forbs (herbaceous flowering plants, $2.8 \%$ ), and bryophytes (mosses, $0.6 \%$ ) (Rehnus et al.
2013). To date, however, food availability has not been incorporated in dietary studies on Alpine mountain hares, resulting in a lack of understanding on diet as a function of locale within the landscape. As an example, it is expected that plant group use will vary across the landscape as the Alpine mountain hare can exist at altitudes between 800 and $2800 \mathrm{~m}$ a.s.1. Not only does the plant composition change along this elevation gradient (Körner 2003; Sundqvist et al. 2013), but plant diversity also decreases with increasing elevation in the Alps (Theurillat et al. 2003).

The overall goal of this study was to investigate the diet of Alpine mountain hares as a function of landscape locale over time. We predicted that (1) the hares' selected diet would be composed of mostly grasses and herbs during the vegetation growth period; (2) the hares' diet breadth would be greater and a larger number of different plant types would be selected at the beginning of the vegetation growth period, since more plant types with new leaves are available at this time than at the end of the vegetation growth period; (3) the hares would have a greater diet breadth and select more different plant types at lower elevations as plant diversity decreases with increasing elevation in the Alps; (4) hares living in landscapes with high plant diversity would exhibit a greater diet breadth and more selected plant types than hares inhabiting landscapes with low plant diversity; (5) higher orders of taxonomic ranking of dietary plants would not lead to a loss of dietary information. We examined these predictions by analyzing the botanical composition of Alpine mountain hare fecal pellets and comparing the obtained results with our assessments of food plant availability at the beginning and end of the vegetation growth period in two different landscape types at different elevation ranges in the Alps during two subsequent years.

\section{Materials and methods}

\section{Study area}

The study was conducted in 2014 and 2015 in two areas located in the Alps near Dalaas $\left(47^{\circ} 7^{\prime} \mathrm{N}, 10^{\circ} 0^{\prime} \mathrm{E}\right)$ in Vorarlberg, Austria. The two areas differed in food diversity and cover characteristics for hares, since they featured very different landscape types. The first area (900 ha, elevation range 1000 to $2000 \mathrm{~m}$ a.s.l.) consisted of a subalpine spruce forest on acidic soil. Due to the soil characteristics, this site featured low plant species diversity. By contrast, the second area ( 1050 ha, elevation range 1600 to $2300 \mathrm{~m}$ a.s.1.) consisted of a species-rich limestone landscape with anthropogenic open areas (i.e., a vegetation mosaic; Jaccard s index comparing the biodiversity levels between the two sites $=0.068$ ). Alpine mountain hares live in both study areas, although they are allopatric at higher elevations and sympatric with the European hares at lower elevations. This information was 
initially provided by local hunters and confirmed through observations made by the research team during the study period. Alpine mountain hares are not hunted in either study area, and tourism within the study areas occurs only during the summer months.

\section{Data collection}

To determine the diet of the mountain hares in the study areas, fecal pellets were collected at the beginning (July) and end (September) of the vegetation growth period in both areas in each year of the study. In total, 58 randomly selected $400 \mathrm{~m}^{2}$ $(20 \times 20 \mathrm{~m}, 0.04 \mathrm{ha})$ plots along the elevation gradient were used for this purpose. The plots were initially cleared of all hare fecal pellets, then revisited three nights later to collect the newly deposited fecal pellets. Feces were mostly found in piles of several pellets likely produced by one individual hare. Each pile was divided into two parts, with one part placed in a 15-ml tube filled with $96 \%$ alcohol for genetic Alpine mountain hare identification and the second part placed in a plastic bag for botanical analysis. To avoid human DNA contamination, fecal pellets were collected with laboratory gloves using a different pair of laboratory gloves for the collection of each set of fecal pellets.

\section{Dietary composition and plant availability}

DNA was extracted from the fecal pellets using the QIAamp DNA Stool Mini Kit (Qiagen, Valencia, California, USA). A molecular marker (219 bp) of the mitochondrial control region was amplified in 311 fecal samples using the primers Lmtof1 and LmtNrl (Palumbi et al. 2002), and sequencing was performed after purification of 171 amplified samples using the Lmtof1 primer. Only fecal pellets confirmed as being from mountain hares (96.5\% of the amplified samples) were considered for further analysis in the paired fecal sample. To determine dietary composition, epidermal fragments in the fecal pellets were identified under a microscope (Chapuis 1990; Reichlin et al. 2006) using a collection of known epidermis samples previously compiled by the project team as reference (see Holechek et al. 1982). The percentage of distinctive plant fragments, identified to the species level if possible, was estimated, with the sum of all plant species percentages found in a set of fecal pellets representing the dietary composition of the specific individual. Plant fractions that accounted for less than $1 \%$ of items were still recorded as being present.

Plant availability in the landscape was determined by taking an inventory of all plants present in each fecal collection plot at each fecal pellet collection timepoint. All plants within a 25 -ha circular plot placed around each 0.04 ha fecal plot were inventoried, as this was assumed to be the respective hares' potential feeding area during the previous $24 \mathrm{~h}$ (Smith et al. 2004). We estimated the percent coverage of non-vital (i.e., woody) and vital (i.e., leafy) parts of each plant species as well as the amount of bare soil (Reichlin et al. 2006). Plant species were identified according to Fischer et al. (2008), with plant nomenclature following Lauber and Wagner (Lauber et al. 2018a). In the field, the Flora Helvetica App was used for species determination (Lauber et al. 2018b). Rare plants (less than $1 \%$ coverage) were still listed as being present. Hares only consume vital plant parts, ignoring non-vital plant parts and bare soil (review in Zörner 1996; Averianov et al. 2003). The sum of the vital parts of all plant species in a 25 -ha circle around fecal plots in which one or more hare fecal pellet piles were found thus comprised the total food available to the respective hares.

\section{Statistical analysis}

All statistical analyses were carried out using the software $\mathrm{R}$ 3.4.2 (R Development Core Team 2018). Dietary selectivity was measured using Chesson's Electivity Index $\varepsilon$ (Chesson 1983), an index based on Manly's alpha selection index (Manly et al. 1972).

$\alpha_{i}=\frac{r_{i}}{n_{i}} \times \frac{1}{\sum_{j=1}^{m}\left(\frac{r_{j}}{n_{j}}\right)}$

(1): Manly's alpha selection index ( $\alpha$ ) (Manly et al. 1972). $\alpha_{i}=$ Manly's selection index for plant species $i ; r_{i}, r_{j}=$ proportions of plant species $i$ and $j$ in the $\operatorname{diet}(i$ and $j=1,2,3, \ldots, m)$; $n_{i}, n_{j}=$ proportions of plant species $i$ and $j$ available; $m=$ number of potential species.

$\varepsilon_{i}=\frac{m \alpha_{i}-1}{(m-2) \alpha_{i}+1}$

(2) Electivity index $\varepsilon$ (Chesson 1983). $m=$ number of potential dietary types, $\alpha_{i}=$ Manly's selection index for plant species $i$.

Chesson's Electivity Index has the advantage that individual dietary preferences are comparable for a varying number of food types available to different individuals (Krebs 1989). The index ranges between -1 and +1 ; negative values are related to avoidance, whereas positive values indicate selection. The Chesson's Electivity Indices were calculated for each plant species, genus, family, and order in each fecal pellet sample. We then examined the Chesson's Electivity Indices across all samples combined as well as between study areas (spruce forest vs. vegetative mosaic), seasons (July vs. September), and low vs. high elevation ranges (i.e., 1200 to $1650 \mathrm{~m}$ a.s.l. versus 1651 to $2099 \mathrm{~m}$ a.s.l.). The reliability of Chesson's Electivity Index was tested by using the bootstrap method (Dixon 1993). The original $\varepsilon_{\mathrm{i}}$ values $\left(\varepsilon_{\mathrm{i}}=\right.$ Chesson's 
Table 1 Comparison of the distribution of Chesson's Electivity Indices over 1000 bootstrap resamples for (a) plant species, (b) plant genera, (c) plant families, and (d) plant orders calculated for all samples combined as well as separately by season, elevation, and study site. The Alpine mountain hare fecal samples were collected in Vorarlberg, Austria, during the years 2014 and 2015. Sample size in brackets is the number of fecal samples in which each plant taxon was found. Note that only plant taxa found in $n \geq 6$ fecal samples are included. Each plant taxon was selected $(+)$, avoided ( - , or not significantly selected (n.s.) by the hares

\begin{tabular}{|c|c|c|c|c|c|c|c|}
\hline a) Plant species & $\begin{array}{l}\text { All } \\
(n=101)\end{array}$ & $\begin{array}{l}\text { July } \\
(n=80)\end{array}$ & $\begin{array}{l}\text { September } \\
(n=21)\end{array}$ & $\begin{array}{l}1200-1650 \mathrm{~m} \\
(n=37)\end{array}$ & $\begin{array}{l}1651-2100 \mathrm{~m} \\
(n=64)\end{array}$ & $\begin{array}{l}\text { Area A } \\
(n=60)\end{array}$ & $\begin{array}{l}\text { Area B } \\
(n=41)\end{array}$ \\
\hline Avenella flexuosa & - & n.s. & - & & - & - & \\
\hline Carex brunnescens & n.s. & n.s. & & & n.s. & n.s. & \\
\hline Carex ferruginea & n.s. & n.s. & & n.s. & n.s. & & n.s. \\
\hline Luzula sylvatica & n.s. & & & & & n.s. & \\
\hline Picea abies & + & n.s. & n.s. & n.s. & + & n.s. & n.s. \\
\hline Rubus idaeus & n.s. & & n.s. & & & n.s. & \\
\hline Sorbus aucuparia & n.s. & & & & & n.s. & \\
\hline Vaccinium myrtillus & n.s. & n.s. & n.s. & n.s. & n.s. & n.s. & n.s. \\
\hline Vaccinium vitis-idaea & n.s. & - & & & n.s. & & - \\
\hline b) Plant genus & $\begin{array}{l}\text { All } \\
(n=101)\end{array}$ & $\begin{array}{l}\text { July } \\
(n=80)\end{array}$ & $\begin{array}{l}\text { September } \\
(n=21)\end{array}$ & $\begin{array}{l}1200-1650 \mathrm{~m} \\
(n=37)\end{array}$ & $\begin{array}{l}1651-2100 \mathrm{~m} \\
(n=64)\end{array}$ & $\begin{array}{l}\text { Area A } \\
(n=60)\end{array}$ & $\begin{array}{l}\text { Area B } \\
(n=41)\end{array}$ \\
\hline Avenella $\mathrm{sp}$ & - & n.s. & - & & - & - & \\
\hline Blechnum $\mathrm{sp}$ & - & & & & - & - & \\
\hline Carex $\mathrm{sp}$ & - & - & n.s. & n.s. & - & - & n.s. \\
\hline Juncus $\mathrm{sp}$ & - & & & & & & \\
\hline Luzula sp. & n.s. & n.s. & & & n.s. & n.s. & \\
\hline Picea $\mathrm{sp}$ & + & n.s. & + & n.s. & + & n.s. & n.s. \\
\hline Poa sp & n.s. & + & & + & n.s. & n.s. & n.s. \\
\hline Rubus sp & n.s. & & n.s. & & & n.s. & \\
\hline Salix $\mathrm{sp}$ & + & + & & + & & & \\
\hline Sorbus sp & n.s. & & & & & n.s. & \\
\hline Vaccinium sp & n.s. & n.s. & n.s. & n.s. & n.s. & n.s. & n.s. \\
\hline c) Plant family & $\begin{array}{l}\text { All } \\
(n=101)\end{array}$ & $\begin{array}{l}\text { July } \\
(n=80)\end{array}$ & $\begin{array}{l}\text { September } \\
(n=21)\end{array}$ & $\begin{array}{l}1200-1650 \mathrm{~m} \\
(n=37)\end{array}$ & $\begin{array}{l}1651-2100 \mathrm{~m} \\
(n=64)\end{array}$ & $\begin{array}{l}\text { Area A } \\
(n=60)\end{array}$ & $\begin{array}{l}\text { Area B } \\
(n=41)\end{array}$ \\
\hline Asteraceae & n.s. & n.s. & & & & & \\
\hline Blechnaceae & n.s. & & & & n.s. & n.s. & \\
\hline Cyperaceae & + & n.s. & n.s. & n.s. & n.s. & + & n.s. \\
\hline Ericaceae & n.s. & n.s. & n.s. & n.s. & n.s. & n.s. & n.s. \\
\hline Fabaceae & n.s. & n.s. & & & & & \\
\hline Juncaceae & - & - & - & & - & - & \\
\hline Pinaceae & + & n.s. & + & n.s. & + & + & n.s. \\
\hline Poaceae & n.s. & + & n.s. & n.s. & n.s. & n.s. & n.s. \\
\hline Rosaceae & n.s. & & n.s. & & n.s. & n.s. & \\
\hline Salicaceae & + & + & & + & & & \\
\hline d) Plant order & $\begin{array}{l}\text { All } \\
(n=100)\end{array}$ & $\begin{array}{l}\text { July } \\
(n=80)\end{array}$ & $\begin{array}{l}\text { September } \\
(n=20)\end{array}$ & $\begin{array}{l}1200-1650 \mathrm{~m} \\
(n=37)\end{array}$ & $\begin{array}{l}1651-2100 \mathrm{~m} \\
(n=63)\end{array}$ & $\begin{array}{l}\text { Area A } \\
(n=59)\end{array}$ & $\begin{array}{l}\text { Area B } \\
(n=41)\end{array}$ \\
\hline Asterales & n.s. & n.s. & & & n.s. & & n.s. \\
\hline Coniferales & n.s. & - & + & n.s. & n.s. & n.s. & n.s. \\
\hline Ericales & + & + & + & + & + & + & + \\
\hline Fabales & n.s. & n.s. & & & & & \\
\hline Malpighiales & n.s. & n.s. & & n.s. & & & \\
\hline Poales & + & + & n.s. & n.s. & + & + & n.s. \\
\hline Polypodiales & - & n.s. & & & n.s. & - & \\
\hline Rosales & n.s. & & n.s. & & - & n.s. & \\
\hline
\end{tabular}


Electivity Index for the food type i) were resampled 1000 times with replacement and an accelerated bootstrap confidence interval was calculated. The accelerated bootstrap adjusted the confidence interval for bias and skewness (Efron and Tibshirani 1993). Bootstrapping was done using the $\mathrm{R}$ package boot (Canty and Ripley 2019). If the lower and upper 95\% CI featured different algebraic signs, the selection of the respective food type was not significant (n.s.). $\varepsilon_{\mathrm{i}}$ values for forage components were only bootstrapped if they were selected by six or more hares, as smaller sample sizes provide unreliable results.

\section{Results}

Alpine mountain hare fecal pellets were collected from 16 plots across an altitudinal range of 1235 to $2073 \mathrm{~m}$ a.s.l., with 9 plots located in the spruce forest and 7 plots located in the vegetation mosaic. Between 1 and 15 piles of fecal pellets with a median of 2 piles $(\mathrm{SD}=2.812)$ were found on each of the plots during each collection visit, and 165 fecal samples from these piles were genetically identified as coming from Alpine mountain hares. Of these, 101 fecal samples-80 of which were collected in July and 21 in September-were analyzed botanically. Of these 101 botanical samples, 37 were collected at an elevation range of 1200 to $1650 \mathrm{~m}$ a.s.l. and 64 at an elevation range of 1651 to $2100 \mathrm{~m}$ a.s.l. In terms of landscape type, 60 of the botanical samples were collected in spruce forest plots and 41 in vegetation mosaic plots. In total, 76 plant species in 68 genera, 37 families, and 23 orders were identified in the fecal pellets (see Online Resource 1), whereas 266 plant species in 173 genera, 63 families, and 36 orders were recorded as being available in the environment (see Online Resource 2).

\section{Overall Alpine mountain hare diet composition}

Nine plant species were found in more than six fecal pellet piles and thus provided reliable Chesson's Electivity Indices (Fig. 1a, Table 1). Of these, one species (Avenella flexuosa) was avoided by Alpine mountain hares, one (Picea abies) was selected, and seven plant species (Carex brunnescens, Carex ferruginea, Luzula sylvatica, Rubus idaeus, Sorbus aucuparia, Vaccinium myrtillus, Vaccinium vitis-idaea) were consumed by the hares in the same proportion as they were available. Eleven plant genera provided reliable Chesson's Electivity Indices (Fig. 1b). Of these, four plant genera (Avenella sp., Blechnum sp., Carex sp., Juncus sp) were avoided, two (Picea sp., Salix sp) were selected, and five (Luzula sp., Poa sp., Rubus sp., Sorbus sp., Vaccinium sp) were consumed neutrally. Of the ten plant families providing reliable indices, one (Juncaceae) was avoided, three (Cyperaceae, Pinaceae, Salicaceae) were selected, and six (Asteraceae,
Blechnaceae, Ericaceae, Fabaceae, Poaceae, Rosaceae) were neutrally consumed by Alpine mountain hares (Fig. 1c). Finally, eight plant orders provided reliable Chesson's Electivity Indices. Of these, one order (Polypodiales) was avoided, two (Ericales, Poales) were selected, and five (Asterales, Coniferales, Fabales, Malpighiales, Rosales) were consumed neutrally by the hares (Fig. 1d).

\section{Effect of taxonomic plant identification level on diet composition}

Selection of specific plant taxa was more frequent at the family (3 families) and order ( 2 orders) levels, while avoidance was more frequently encountered at the genus (4 genus) level (Fig. 2, Table 1). Despite most of the Chesson's Electivity Indices being neutral across all identification levels, identification at the genus level revealed the most information in terms of hare selection and avoidance tendencies (Fig. 2), followed by the family and order levels. Little additional information could be gleaned at the species level, and trends were typically consistent from the genus to the order level (Fig. 2). Furthermore, plant identification at the genus level revealed the highest number of calculated indices $(+,-$, n.s.).

\section{Influence of landscape type on diet composition}

Hares exhibited a greater diet breadth in the low-diversity spruce forest landscape, where they consumed 9 genera $(7$ species, 7 families, 5 orders) of plants; in the mosaic vegetation landscape, they consumed only 4 genera ( 4 species, 4 families, 4 orders; Fig. 3; Table 1). While there was a higher variety in the diet of hares within spruce forests, the individuals also had negative associations with more plant types within this habitat, choosing them less often than they were available (Fig. 3). Hares in low-diversity habitats frequently consumed plants of the same families as hares in mosaic habitats, although the hares in mosaic habitats also consumed flowering plants of the order Asterales (Fig. 3). For both habitat types, the largest number of positive associations with plants occurred at the order level (Fig. 3). Only the plant order Ericales was selected in both landscape types.

\section{Influence of vegetation period on diet composition}

Diet breadth was greater at the beginning ( 6 species, 7 genera, 8 families, 7 orders) than at the end (4 species, 5 genera, 6 families, 4 orders) of the vegetation growth period (Fig. 4, Table 1). Plants of certain orders (Asterales, Polypodiales, Fabales, Malpighiales) were only consumed at the beginning of the vegetation growth period, whereas one was used only at the end of the vegetation growth period (Rosales; Fig. 4). Hares fed on plants of the orders Poales, Coniferales, and 
Fig. 1 Chesson's Electivity Indices in Alpine mountain hare feces $(n=101)$ and their distributions over 1000 bootstrap resamples (mean and 95\% confidence interval) for (a) plant species, (b) plant genera, (c) plant families, and (d) plant orders found in $n \geq 6$ fecal samples (sample size in brackets is the number of fecal samples in which each plant species/genus/family/ order was found). The fecal samples were collected in Vorarlberg, Austria, during the years 2014 and 2015. Nonsignificant results cross the vertical line at zero. See text for statistical details
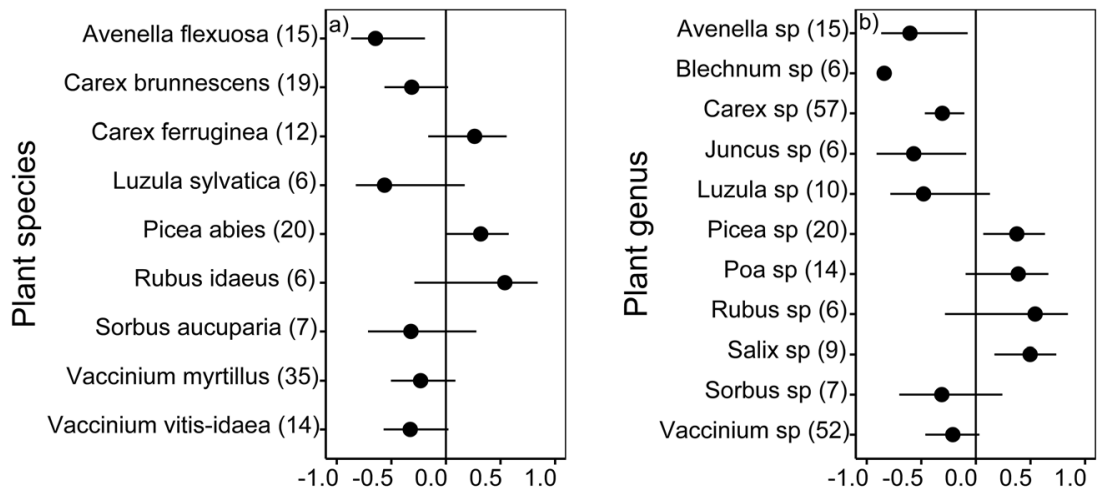

Electivity index

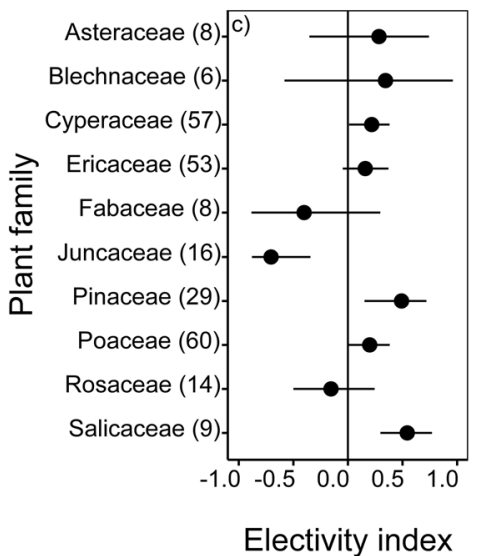

Electivity index

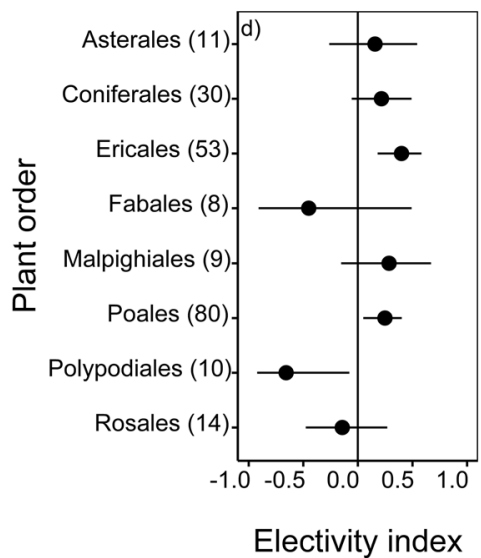

Ericales throughout the vegetation growth period. They had more positive than negative associations with specific plant types at the beginning of the vegetation growth period, choosing them more often than avoiding them. By comparison, positive and negative associations were balanced at the end of the vegetation growth period (Fig. 4). Only at the family and the order level could a few similarities in regard to avoidance and selection be determined: the plant family Juncaceae was avoided at both the beginning and end of the vegetation growth period, while the plant order Ericales was selected throughout the vegetation growth period (Fig. 4).

\section{Influence of elevation range on diet composition}

Hares showed a greater diet breadth at high elevations, consuming 7 families ( 6 species, 7 genera, 6 orders) of plants compared to hares inhabiting low elevations, which only consumed 5 families (3 species, 4 genera, 4 orders; Fig. 5; Table 1). While there was a higher variety in the diet of hares at high elevations, they also had more negative than positive associations with plant types (Fig. 5). At low elevations with lower dietary variety, hares had only positive and no negative associations with plant types (Fig. 5). Plants of the order Ericales were selected regardless of the elevation range (Fig. 5).

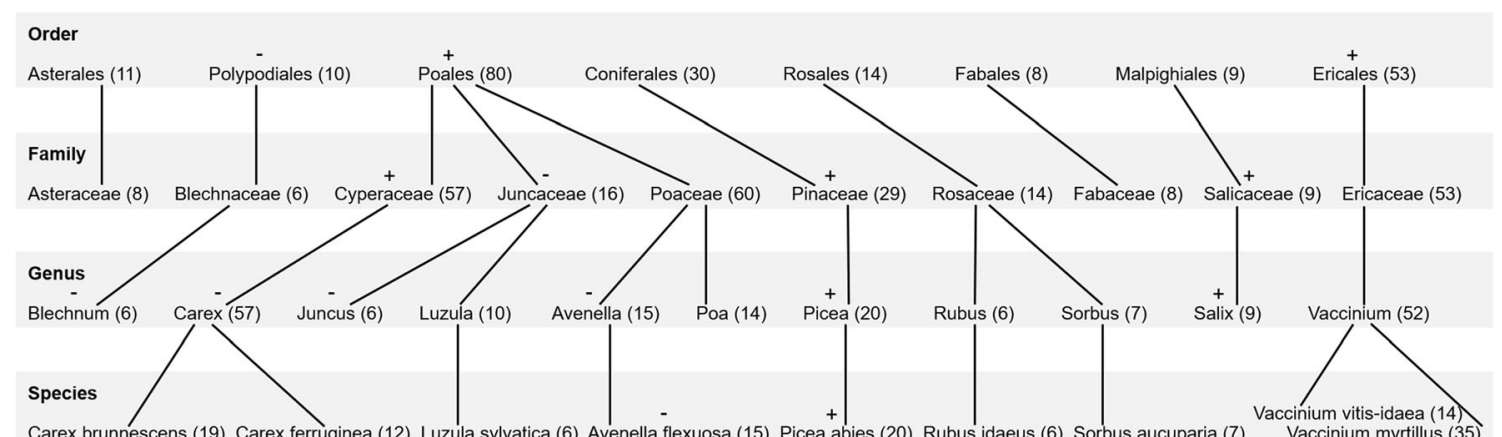

Fig. 2 Number of positive (+), negative (-), and non-significant distributions of Chesson's Electivity Indices over 1000 bootstrap resamples determined at different taxonomic identification levels. The Alpine mountain hare fecal samples $(n=101)$ were collected in Vorarlberg, Austria, during the years 2014 and 2015. Note that only plant taxa found in $n \geq 6$ fecal samples are included 


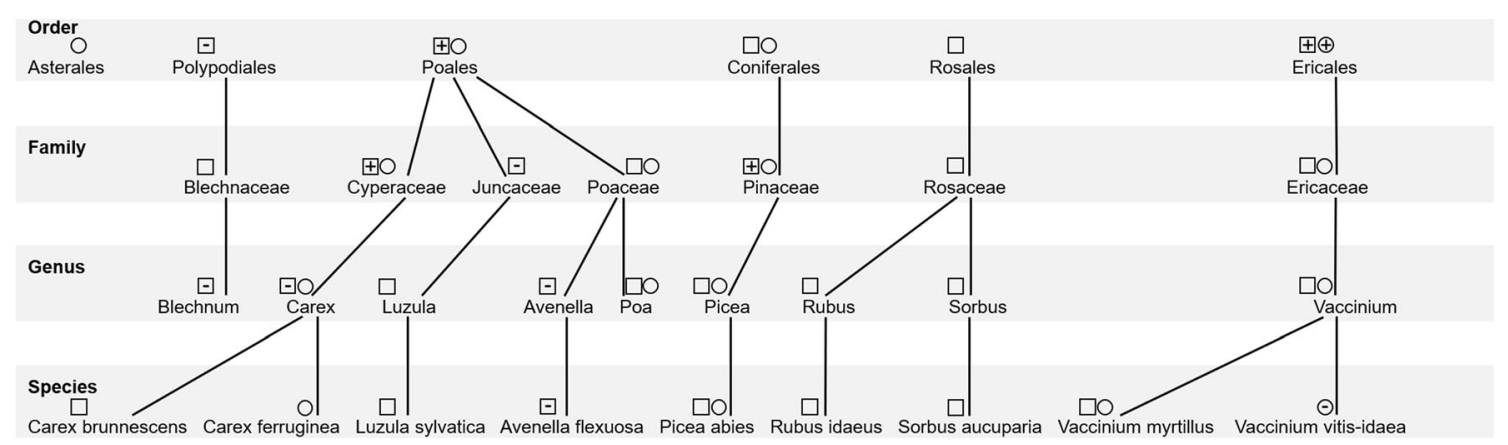

Fig. 3 Comparison of the distribution of Chesson's Electivity Indices over 1000 bootstrap resamples for plant species, plant genera, plant families, and plant orders by study area. The Alpine mountain hare fecal samples were collected in Vorarlberg, Austria, during the years 2014 and 2015. Squares represent the spruce forest landscape with low

\section{Discussion}

\section{Alpine mountain hare diet composition}

Despite the fact that various diet analyses of hares in general (Schai-Braun and Hackländer 2016) as well as of mountain hares (Hewson 1962; Johannessen and Samset 1994; Dingerkus and Montgomery 2001) or Alpine mountain hares (Rehnus et al. 2013) have shown that grasses are a major food component, our study revealed that Alpine mountain hares did not select for any grass species (family Poaceae) - in fact, the only plant species avoided was a grass species (Avenella flexuosa). The only identified plant species selected by the hares was a conifer, which corroborates previous literature indicating that the major portion of the Alpine mountain hare's diet is gymnosperms (Rehnus et al. 2013). Furthermore, several of the neutrally consumed species (sedges, dwarf shrubs) were in agreement with the broad taxonomic plant groups describing the diet of the Alpine mountain hare (Rehnus et al. 2013). Overall dietary selections remained the same at the genus and family levels. Trees were selected (Picea sp., Salix sp. respectively Pinaceae, Salicaceae), whereas grasses and dwarf shrubs plant species diversity, whereas circles represent the mosaic vegetation landscape with high plant species diversity. Note that only plant taxa found in $n \geq 6$ fecal samples are included. Plant taxon was selected (+), avoided (-), or not significantly selected by the hares

were neutrally consumed (Poa sp., Vaccinium sp. respectively Ericaceae, Poaceae). However, diet selection changed at the order level. Ericales and Poales were selected, which is in line with previous literature (Hewson 1962; Dingerkus and Montgomery 2001; Rehnus et al. 2013; Schai-Braun and Hackländer 2016), whereas Coniferales were neutrally consumed. The change in dietary selections at the order level may be reflective of the fact that various families are merged into one order in the Alps.

\section{Effect of taxonomic plant identification level}

The most informative taxonomic level of plant identification was the genus level, as it produced the highest total number $(n=48)$ of calculated selection indices across both elevation ranges and landscape types as well as throughout the vegetation growth period. At the family and order level, knowledge gain was roughly the same across our variables of interest $(n=$ 15 and 16 indices, respectively). By far, the least amount of information was obtained at the species level of plant identification. This is due to the fact that plant fragments in fecal pellets may be identified imperfectly due to the digestion

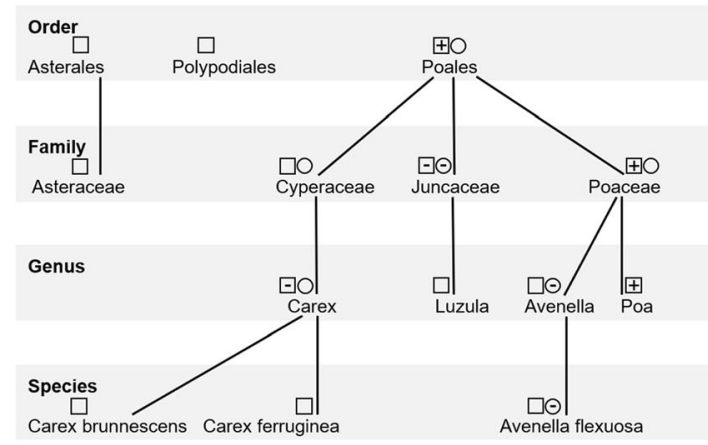

Fig. 4 Comparison of the distribution of Chesson's Electivity Indices over 1000 bootstrap resamples for plant species, plant genera, plant families, and plant orders by vegetation growth period. The Alpine mountain hare fecal samples were collected in Vorarlberg, Austria, during the years 2014 and 2015. Squares represent the beginning of the

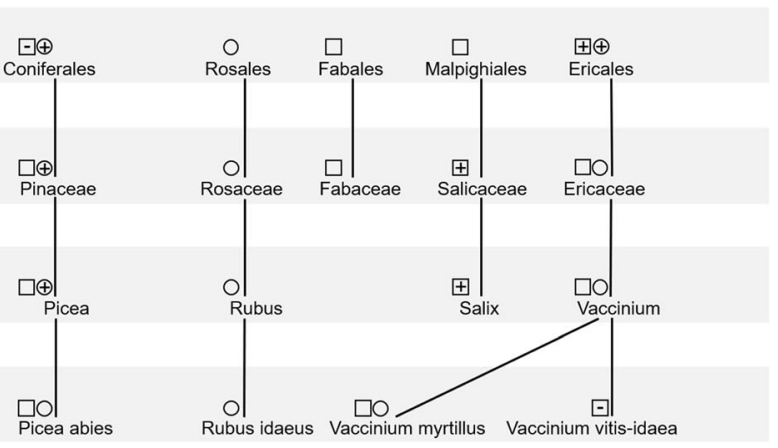

vegetation growth period (July), whereas circles represent the end of the vegetation growth period (September). Note that only plant taxa found in $n \geq 6$ fecal samples are included. Symbols indicate that a plant taxon was selected (+), avoided (-), or not significantly selected by the hares 


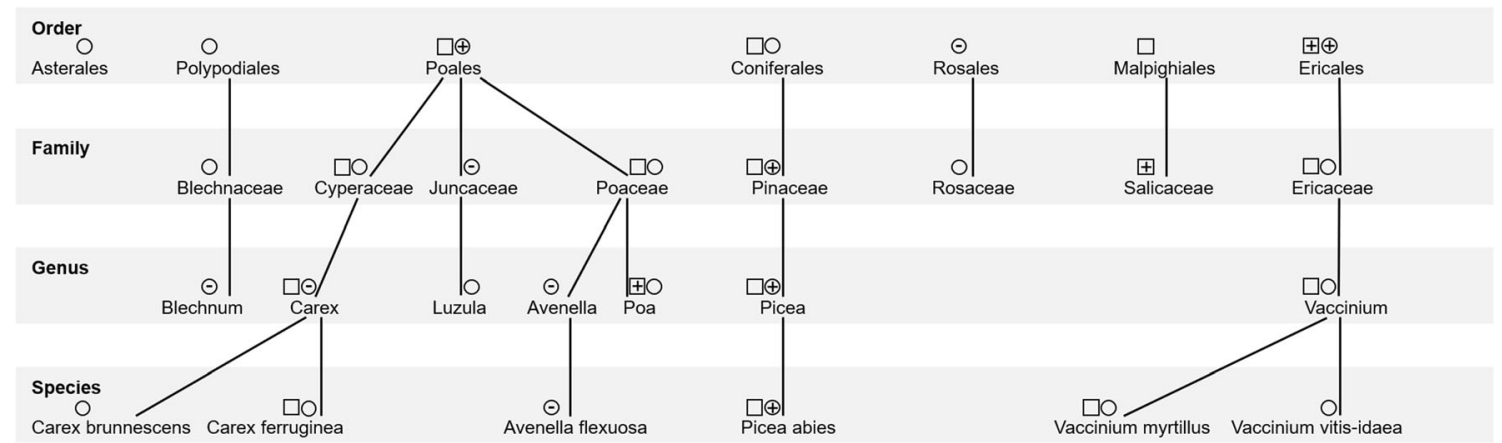

Fig. 5 Comparison of the distribution of Chesson's Electivity Indices over 1000 bootstrap resamples for plant species, plant genera, plant families, and plant orders by elevation range. The Alpine mountain hare fecal samples were collected in Vorarlberg, Austria, during the years 2014 and 2015. Squares represent low elevation ranges (1200 to

processes (Putman 1984) and, possibly, due to the deterioration of the fecal pellets in the air (Chapman 2004; Phillips et al. 2018). It is possible to avoid these potential constraints in the future by using DNA barcoding (Valentini et al. 2009; Ibanez et al. 2013), though we recognize the economic constraints this method entails. If DNA barcoding is not possible but selections at the species level are relevant, we therefore suggest calculating the indices at the genus level as well to further clarify the effect of taxonomic plant identification level on the results.

\section{Influence of landscape type on diet composition}

Hares in the spruce forest landscape frequently consumed the same types of plants as hares in the mosaic landscape. This suggests that hares in the spruce forest had access to the same types of plants (other than Asterales) as those in the mosaic landscape. Interestingly, hares inhabiting the spruce forest landscape with low plant diversity exhibited a greater diet breadth than those living in the mosaic landscape with high plant diversity. However, hares in the spruce forest landscape chose numerous plant types less often than they were available. This may indicate that these hares do not have access to certain plant types in the quantity they require and therefore have to diversify their selection of food plants. It seems as though less diet variability is necessary for herbivorous mammals such as the Alpine mountain hare in diverse habitats than in homogenous habitats, as there are enough nutritious food plants available.

\section{Influence of vegetation period on the diet selection of Alpine mountain hares}

In accordance with other diet and diet preference studies (e.g., Nissen et al. 2013; Requier et al. 2015), the selections and avoidances of Alpine mountain hares varied broadly between the beginning and end of the vegetation growth period due to
$1650 \mathrm{~m}$ a.s.1.), whereas circles represent high elevation ranges (1651 to $2099 \mathrm{~m}$ a.s.l.). Note that only plant taxa found in $n \geq 6$ fecal samples are included. Symbols indicate that a plant taxon was selected (+), avoided $(-)$, or not significantly selected by the hares

changing food availability. Plant availability throughout the growth period is probably the reason why some plant orders were consumed only at the beginning or the end of the vegetation growth period and some throughout the entire vegetation growth period. At all taxon levels, the diet breadth was greater at the beginning than at the end of the vegetation period. Furthermore, the hares had more positive than negative associations with plant types at the beginning of the vegetation growth period, suggesting that more suitable food sources were available at the beginning of the growth period than at its end. We recorded an avoidance of the plant family Juncaceae (representatives: Juncus inflexus, Juncus sp., Luzula multiflora, Luzula sylvatica, Luzula sp) throughout the vegetation period, which seems to indicate that Alpine mountain hares have enough other plant families available throughout the vegetation growth period to avoid Juncaceae as food plants. The plant order Ericales was continuously selected throughout the vegetation growth period in both elevation ranges and in both landscape types. This implies that appropriate plant species of this order were not only available throughout the vegetation period in both elevation ranges and in both landscape types, but also that these plants (representatives: Erica carnea, Vaccinium gaultherioides, Vaccinium myrtillus, Vaccinium vitis-idaea, Vaccinium sp., Primula farinosa) were highly attractive to the Alpine mountain hares.

\section{Influence of elevation range on diet composition}

Comparing the diet of hares inhabiting low and high elevation ranges revealed similar results as the comparison between low and high plant diversity landscapes. At higher elevations, hares showed a higher variety in their diet and more negative associations with plant types than at lower elevations. We suggest that the hares do not have access to the preferred plant types in the quantity they need at higher elevation ranges and are thus forced to diversify their food sources. 


\section{Conclusion}

In conclusion, our results imply that Alpine mountain hares prefer ligneous plants even when grasses and herbs are available, whereas grasses are neutrally consumed or even avoided. The number of findings obtained by calculating preference indices was highest at the genus level of plant identification, whereas by far, the least information was gleaned at the species level. Hares inhabiting landscapes with low plant diversity or at higher elevations exhibited a higher variety in their diet and more negative associations with plant types than hares living in landscapes with high plant diversity or at lower elevations. We suggest that hares do not have access to their preferred plant types in the quantity they need in landscapes with low plant diversity or at higher elevations, and that they have to diversify their consumed food plant types as a result.

Acknowledgments We would like to thank Lorie Baker, Natalie Eder, Elisabeth Hatzmann, and Gernot Heigl for their help with data collection. We also thank João Queirós for his help with genetic analysis. We are grateful to the hunters of the Dalaas hunting district for their cooperation, especially hunting district supervisor Manfred Vonbank for his continuous assistance and Caroline Egger for her valuable support. This study complies with the current laws of Austria.

Funding information Open access funding provided by University of Natural Resources and Life Sciences Vienna (BOKU). This study was funded by Stotzer-Kästli-Stiftung, Temperatio, Giacometti, Verein Grünes Kreuz, Carl Burger Stiftung, Margarethe und Rudolf GsellStiftung, NAKUSO-Stiftung, Graf Fabrice, von Gundlach und Payne Smith-Stiftung, Basler Stiftung für biologische Forschung, and a Research Stimulation Grant provided by the Department of Integrative Biology and Biodiversity Research at the University of Natural Resources and Life Sciences, Vienna.

\section{Compliance with ethical standards}

Conflict of interest The authors declare that they have no conflict of interest.

Ethical approval This article does not contain any studies with human participants or animals performed by any of the authors.

Open Access This article is licensed under a Creative Commons Attribution 4.0 International License, which permits use, sharing, adaptation, distribution and reproduction in any medium or format, as long as you give appropriate credit to the original author(s) and the source, provide a link to the Creative Commons licence, and indicate if changes were made. The images or other third party material in this article are included in the article's Creative Commons licence, unless indicated otherwise in a credit line to the material. If material is not included in the article's Creative Commons licence and your intended use is not permitted by statutory regulation or exceeds the permitted use, you will need to obtain permission directly from the copyright holder. To view a copy of this licence, visit http://creativecommons.org/licenses/by/4.0/.

\section{References}

Averianov A, Niethammer J, Pegel M (2003) Lepus europaeus Pallas, 1778 - Feldhase. In: Niethammer J, Krapp F (eds) Handbuch der Säugetiere Europas, Band 3/II Hasentiere. AULA-Verlag, Wiesbaden, pp 35-104

Brown J, Gillooly J, Allen A, van Savage M, West G (2004) Toward a metabolic theory of ecology. Ecol. 85(7):1771-1789

Cantalapiedra JL, FitzJohn RG, Kuhn TS, Hernández Fernández M, DeMiguel D, Azanza B, Morales J, Mooers AØ (2014) Dietary innovations spurred the diversification of ruminants during the Caenozoic. P Roy Soc B-Biol Sci 281(1776):20132746

Canty A, Ripley B (2019) boot: Bootstrap R (S-Plus) functions. R package version 1.3-22. http://CRAN.R-project.org/package=boot

Chapman NG (2004) Faecal pellets of Reeves' muntjac, Muntiacus reevesi: defecation rate, decomposition period, size and weight. Eur J Wildl Res 50:141-145. https://doi.org/10.1007/s10344-0040053-0

Chapuis JL (1990) Comparison of the diets of two sympatric lagomorphs, Lepus europaeus (Pallas) and Oryctolagus cuniculus (L.) in an agroecosystem of the Ile-de-France. Z Säugetierkd 55:176-185

Chesson J (1983) The estimation and analysis of preference and its relationship to foraging models. Ecol. 64:1297-1304

Cornelis J, Casaer J, Hermy M (1999) Impact of season, habitat and research techniques on diet composition of roe deer (Capreolus capreolus): a review. J Zool 248:195-207

Development Core Team R (2018) R: a language and environment for statistical computing. R Foundation for Statistical Computing, Vienna www.R-project.org

Dingerkus S, Montgomery WI (2001) The diet and landclass affinities of the Irish hare Lepus timidus hibernicus. J Zool (London) 253:233240

Dixon PM (1993) The bootstrap and the jackknife: describing the precision of ecological indices. In: Scheiner SM, Gurevitch J (eds) Design and analysis of ecological experiments. Chapman and Hall, pp 290-318

Duffy J (2002) Biodiversity and ecosystem function: the consumer connection. Oikos. 99(2):201-219

Efron B, Tibshirani RJ (1993) An introduction to the bootstrap. Monographs on statistics and applied probability 57 . Chapman and Hall

Erickson D, Reed E, Ramachandran P, Bourg N, McShea W, Ottesen A (2017) Reconstructing a herbivore's diet using a novel rbcL DNA mini-barcode for plants. AoB Plants 9:3 plx015

Fischer MA, Oswald K, Adler W (2008) Exkursionsflora für Österreich, Liechtenstein, Südtirol, 3rd edn. Biologiezentrum des Oberösterreichischen Landesmuseums, Linz

Halstead B, Mushinsky H, McCoy E (2008) Sympatric Masticophis flagellum and Coluber constrictor select vertebrate prey at different levels of taxonomy. Copeia. 2008(4):897-908. https://doi.org/10. 1643/CE-07-221

Hewson R (1962) Food and feeding habits of the mountain hare Lepus timidus scoticus. Hilzheimer Proc Zool Soc Lond 139:515-526

Holechek JL, Vavra M, Pieper RD (1982) Botanical composition determination of range herbivore diets: a review. J Range Manag 35(3): 309-315

Hulbert IAR, Iason GR (1996) The possible effects of landscape change on diet composition and body weight of mountain hares Lepus timidus. Wildl Biol 2(4):269-273

Ibanez S, Manneville O, Miquel C, Taberlet P, Valentini A, Aubert S, Coissac E, Colace M-P, Duparc Q, Lavorel S, Moretti M (2013) Plant functional traits reveal the relative contribution of habitat and food preferences to the diet of grasshoppers. Oecol. 173(4):14591470 
Jennings N, Smith RK, Hackländer K, Harris S, White PCL (2006) Variation in demography, condition and dietary quality of hares Lepus europaeus from high-density and low-density populations. Wildlife Biol 12(2):179-189

Johannessen V, Samset E (1994) Summer diet of the mountain hare (Lepus timidus $\mathrm{L}$.) in a low-alpine area in southern Norway. Can $\mathrm{J}$ Zool 72(4):652-657

Kauhala K, Ihalainen A (2014) Impact of landscape and habitat diversity on the diversity of diets of two omnivorous carnivores. Acta Theriol 59(1):1-12. https://doi.org/10.1007/s13364-013-0132-2

Kissling WD, Böhning-Gaese K, Jetz W (2009) The global distribution of frugivory in birds. Glob Ecol Biogeogr 18(2):150-162. https://doi. org/10.1111/j.1466-8238.2008.00431.x

Kissling WD, Sekercioglu CH, Jetz W (2012) Bird dietary guild richness across latitudes, environments and biogeographic regions. Glob Ecol Biogeogr 21(3):328-340. https://doi.org/10.1111/j.14668238.2011.00679.x

Körner C (2003) Alpine plant life. Functional plant ecology of high mountain ecosystems, 2nd edn. Springer, Berlin

Krebs CJ (1989) Measurement of dietary preferences. In: Wilson MW, Pisano S (eds) Ecological methodology. HarperCollins, New York, pp 392-407

Lauber K, Wagner G, Gygax A (2018a) Flora helvetica. Haupt Verlag, Berne

Lauber K, Wagner G, Gygax A (2018b) Flora helvetica app (iOS and android). Haupt Verlag, Berne www.flora-helvetica.ch

Manly BFJ, Miller P, Cook LM (1972) Analysis of a selective predation experiment. Am Nat 106:719-736

Navarro-López J, Fargallo J (2015) Trophic niche in a raptor species: the relationship between diet diversity, habitat diversity and territory quality. PLoS One 10(6):e0128855. https://doi.org/10.1371/ journal.pone. 0128855

Nissen H, Krüger F, Fichtner A, Sommer R (2013) Local variability in the diet of Daubenton's bat (Myotis daubentonii) in a lake landscape of northern Germany. Folia Zool 62(1):36-41. https://doi.org/10. 25225/fozo.v62.i1.a5.2013

Palumbi S, Martin A, Romano S, McMillan WO, Stice L, Grabowski G (2002) The simple fool's guide to PCR. Department of Zoology and Kewalo Marine Laboratory. University of Hawaii, Honolulu

Phillips CA, Woolley C, Mann D, McGrew WC (2018) Disappearance rate of chimpanzee scats: implications for census work on Pan troglodytes. Afr J Ecol 56(2):168-178

Price SA, Hopkins SSB, Smith KK, Roth VL (2012) Tempo of trophic evolution and its impact on mammalian diversification. PNAS. 109(18):7008-7012

Putman RJ (1984) Facts from faeces. Mammal Rev 14(2):79-97

Rehnus M, Marconi L, Hackländer K, Filli F (2013) Seasonal changes in habitat use and feeding strategy of the mountain hare (Lepus timidus) in the Central Alps. Hystrix. 24(2):161-165. https://doi. org/10.4404/hystrix-24.2-4703
Reichlin T, Klansek E, Hackländer K (2006) Diet selection by hares (Lepus europaeus) in arable land and its implications for habitat management. Eur J Wildl Res 52(2):109-118. https://doi.org/10. 1007/s10344-013-0723-x

Requier F, Odoux J-F, Tamic T, Moreau N, Henry M, Decourtye A, Bretagnolle V (2015) Honey bee diet in intensive farmland habitats reveals an unexpectedly high flower richness and a major role of weeds. Ecol Appl 25(4):881-890

Schai-Braun SC, Hackländer K (2016) Family Leporidae. Hares and rabbits. In: Wilson DE, Lacher TE Jr, Mittermeier RA (eds) Handbook of the mammals of the world - Volume 6. Lagomorphs and rodents I. Lynx Edicions, Barcelona, pp 62-148

Schai-Braun SC, Reichlin TS, Ruf T, Klansek E, Tataruch F, Arnold W, Hackländer K (2015) The European hare (Lepus europaeus): a picky herbivore searching for plant parts rich in fat. PLoS One 10(7):e0134278

Seccombe-Hett P, Turkington R (2008) Summer diet selection of snowshoe hares: a test of nutritional hypotheses. Oikos 117(12):18741884

Simberloff D, Dayan T (1991) The guild concept and the structure of ecological communities. Annu Rev Ecol Syst 22(1):115-143

Smith JNM, Krebs CJ, Sinclair ARE, Boonstra R (1988) Population biology of snowshoe hares. II. Interactions with winter food plants. J Anim Ecol 57(1):269

Smith RK, Jennings NV, Robinson A, Harris S (2004) Conservation of European hares Lepus europaeus in Britain: is increasing habitat heterogeneity in farmland the answer? J Appl Ecol 41:1092-1102

Sundqvist M, Sanders N, Wardle D (2013) Community and ecosystem responses to elevational gradients: processes, mechanisms, and insights for global change. Annu Rev Ecol Evol Syst 44(1):261-280

Szép D, Bocz R, Purger J (2018) Weather-dependent variation in the winter diet of urban roosting long-eared owls (Asio otus) in Pécs (Hungary). Avian Biol Res 11(1):1-6

Theurillat J-P, Schlüssel A, Geissler P, Guisan A, Velluti C, Wiget L (2003) Vascular plant and bryophyte diversity along elevation gradients in the Alps. In: Baldwin IT, Caldwell MM, Heldmaier G, Lange OL, Mooney HA, Schulze E-D, Sommer U, Nagy L, Grabherr G, Körner C, Thompson DBA (eds) Alpine biodiversity in Europe (Ecological Studies), Bd. 167. Springer Berlin Heidelberg, Berlin, pp 185-193

Valentini A, Miquel C, Nawaz M, Bellemain E, Coissac E, Pompanon F, Gielly L, Cruaud C, Nascetti G, Wincker P, Swenson J, Taberlet P (2009) New perspectives in diet analysis based on DNA barcoding and parallel pyrosequencing: the trnL approach. Mol Ecol Resour 9(1):51-60

Zörner E (1996) Der Feldhase. Spektrum Akademischer Verlag, Heidelberg

Publisher's note Springer Nature remains neutral with regard to jurisdictional claims in published maps and institutional affiliations. 